\title{
At-Home HSCT
}

\author{
Francesc Fernandez-Avilés \\ and Gonzalo Gutiérrez-García
}

\subsection{Autologous HSCT}

\subsubsection{Introduction}

Toxicity and mortality associated with autoHSCT have been reduced, and outpatient parenteral antimicrobial treatment has been proven feasible and safe, thanks to modern CVC and infusion devices. These advances have led to the development of outpatient auto-HSCT programs, and several studies have demonstrated their feasibility and safety.

There are various reasons for transferring the support of the neutropenic phase of auto-HSCT to the ambulatory setting, including patient preference, reduced exposure to hospital microorganisms, better use of hospital resources, and cost-saving issues (Meisenberg et al. 1997). In this model, however, patients experience timeconsuming daily travel to the outpatient clinic for blood tests and physician checkups. "Hospital at home" is an alternative, designed to reduce hospital outpatient admissions by providing hospital equivalent care to patients in the home setting (Westermann et al. 1999; Fernández Avilés et al. 2006).

\subsubsection{Ambulatory Auto-HSCT Models}

\begin{tabular}{|c|c|}
\hline \multicolumn{2}{|c|}{ Complete outpatient program (Holbro et al. 2013) } \\
\hline $\begin{array}{l}\text { Conditioning regimen, } \\
\text { HPC and management of } \\
\text { the aplastic phase }\end{array}$ & Outpatient clinics \\
\hline \multicolumn{2}{|c|}{ Delayed admission (Anastasia et al. 2009) } \\
\hline $\begin{array}{l}\text { Conditioning regimen and } \\
\text { HPC infusion }\end{array}$ & Inpatient \\
\hline $\begin{array}{l}\text { Management of the } \\
\text { aplastic phase }\end{array}$ & $\begin{array}{l}\text { Early discharge }(+1) \text { and } \\
\text { readmission }(+5)\end{array}$ \\
\hline \multicolumn{2}{|c|}{ Mixed inpatient-outpatient (Morabito et al. 2002) } \\
\hline Conditioning regimen & Outpatient clinics \\
\hline HPC infusion & Inpatient \\
\hline $\begin{array}{l}\text { Management of the } \\
\text { aplastic phase }\end{array}$ & Outpatient clinics \\
\hline \multicolumn{2}{|c|}{ Early discharge outpatient (Martino et al. 2014) } \\
\hline $\begin{array}{l}\text { Conditioning regimen and } \\
\text { HPC infusion }\end{array}$ & Inpatient \\
\hline $\begin{array}{l}\text { Management of the } \\
\text { aplastic phase }\end{array}$ & Outpatient clinics \\
\hline \multicolumn{2}{|c|}{ Early discharge at home (Fernández Avilés et al. 2006) } \\
\hline $\begin{array}{l}\text { Conditioning regimen and } \\
\text { HPC infusion }\end{array}$ & Inpatient \\
\hline $\begin{array}{l}\text { Management of the } \\
\text { aplastic phase }\end{array}$ & At home \\
\hline
\end{tabular}

F. Fernandez-Avilés $(\bowtie) \cdot$ G. Gutiérrez-García Department of Hematology, Bone Marrow Transplantation Unit, Hospital Clínic de Barcelona, Universitat de Barcelona, Barcelona,

Catalunya, Spain

e-mail: ffernand@clinic.cat 


\subsubsection{Inclusion Criteria for Ambulatory Auto-HSCT}

\begin{tabular}{|l|l|}
\hline Patient & - Age $\leq 65$ years \\
& - ECOG $\leq 2$ \\
& - Normal cardiac, lung, liver, and renal \\
& function \\
& - Recent documented infection with a \\
& proven secondary prophylaxis \\
& - Absence of refractoriness to platelet \\
& transfusion
\end{tabular}

\subsubsection{General Recommendations for At-Home Auto-HSCT}

Dose of CD34+ cells, use of G-CSF after HPC infusion, primary antimicrobial prophylaxis, and supportive care (hydration, management of emesis and metabolic disorders, analgesic therapy, and transfusion of blood products) should not differ from that recommended for conventional auto-HSCT. All these treatments can routinely be performed at home or in outpatient clinic.

\subsubsection{Most Frequent Reasons for Readmission (Ordered by Frequency)}

Persistent fever $>38{ }^{\circ} \mathrm{C}$ without identified infectious focus

Severe oral mucositis or gastrointestinal toxicity (WHO grade III or IV) with insufficient liquid intake

Severe sepsis with organic failure

Request of the patient (psychological distress) or loss of caregiver support

\subsubsection{Treatment of Fever in At-Home Setting}

If fever occurs, the patient should be evaluated quickly by an expert hematologist on call. The use of empiric antibacterial treatment should follow guidelines/recommendations for patients with hematologic malignancies and neutropenic fever. IV antibiotics should be preferred and chosen in the light of clinical and laboratory findings. After at least $6 \mathrm{~h}$ monitoring, hemodynamically stable patients without relevant clinical problems may be followed at home. Table 63.1 shows the different empiric antibiotic therapy that could be used at home.

\subsubsection{Incidence of Readmission in Outpatient and At-Home Auto-HSCT}

The incidence of readmissions is closely related to the experience of the group of professionals in outpatient or at-home management of complications and by the support infrastructure available in the hospital.

Table 63.1 Empirical antibiotic therapy

Patients not receiving prophylaxis with quinolones Levofloxacin (PO or IV)

Moxifloxacin PO

Ciprofloxacin PO associated or not to amoxicillin/ clavulanate

Ciprofloxacin PO associated or not to linezolid PO

Patients receiving prophylaxis with quinolones

IV ceftriaxone or piperacillin/tazobactam ${ }^{\mathrm{a}}$ or meropenem ${ }^{\mathrm{b}}$ associated to teicoplanin $\mathrm{IV}^{\mathrm{c}}$ if intense oral mucositis

If there is a high suspicion of CVC infection, add teicoplanin and an anti-GNB such as amikacin IV and evaluate the CVC withdrawal

If allergic to beta-lactam: quinolones PO/IV associated with teicoplanin IV and amikacin IV

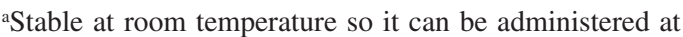
home by electronic intermittent infusion pump

${ }^{b}$ Accurate refrigeration to achieve adequate stability for home administration

${ }^{\mathrm{c}}$ The first option at home would be teicoplanin once daily instead of vancomycin IV (twice a day). Other alternatives rarely necessary in the context of auto-HSCT are daptomycin IV or linezolid PO 
In patients with $M M$, usually conditioned with MEL, the lowest readmission rates have been reported (between 10 and 20\%) due to the low organic toxicity (Martino et al. 2016). They are clearly the best option when considering starting an outpatient or at-home auto-HSCT program.

In patients with $N H L$ or $H L$ usually conditioned with a more toxic regime (BEAM or BEAC), there is a significantly higher readmission rate, between 30 and $90 \%$, according to the series (Faucher et al. 2012; Scortechini et al. 2014).

In the hospital clinic at-home auto-HSCT experience, the low rate of febrile neutropenia is achieved, thanks to the intensification of antibiotic prophylaxis (ceftriaxone in MM and piperacillin/tazobactam in NHL and LH patients), and the successful control of fever at home resulted in an overall readmission rate significantly lower $(8.5 \%)$ in a series of 325 patients.

\subsubsection{Quality of Life}

The data published are limited and contradictory. Thus, (Summers et al. 2000) reported significantly higher scores for emotional well-being and global QOL in outpatients, while (Martino et al. 2018) indicated that the outpatient model neither improves nor impairs global patient QOL on the first 30 days after auto-HSCT. In this sense (Schulmeister et al. 2005) reported that the QOL decreased immediately post treatment but then increased to above pretreatment levels by 6 months. A good clinical outcome following auto-HSCT was associated with better QOL and greater satisfaction with care.

\subsubsection{Cost Data}

The study of "real" costs of these ambulatory/ domiciliary auto-HSCT programs is still to be carried out. In the absence of well-designed studies aimed at evaluating the "real" savings achieved with outpatient/at-home auto-HSCT programs, some authors cite direct savings between $10 \%$ and
50\% (Meisenberg et al. 1998; Fernández Avilés et al. 2006; Holbro et al. 2013), especially influenced by the release of hospital beds and low readmission rates.

\subsection{Allogeneic HSCT}

\subsubsection{Introduction}

The consolidation of ambulatory auto-HSCT modalities as a safe and potentially cost-saving procedure and the introduction of NMA and RIC conditioning chemotherapies minimizing toxicity have allowed the development of alloHSCT ambulatory programs. Indeed, the main relevant results with this type of modality have shown a safe profile in terms of lower rate of infection and GVHD improving QOL, conditions that should expand the development of ambulatory modalities into the allo-HSCT setting (Svahn et al. 2002). However, after two decades of the first ambulatory allo-HSCT program, the experience with this modality is limited to few BMT groups.

\subsubsection{Ambulatory Allo-HSCT Models}

\begin{tabular}{|c|c|}
\hline Complete outpatient program (McI & mid et al. 2010) \\
\hline $\begin{array}{l}\text { Conditioning regimen and HPC } \\
\text { infusion }\end{array}$ & $\begin{array}{l}\text { Outpatient } \\
\text { clinics }\end{array}$ \\
\hline Management of the aplastic phase & \\
\hline Mixed inpatient-outpatient (Solom & t al. 2010) \\
\hline Conditioning regimen & Outpatient clinic \\
\hline HPC infusion & Inpatient \\
\hline Management of the aplastic phase & Outpatient clinic \\
\hline Early discharge at home (Ringdén & 1. 2018) \\
\hline $\begin{array}{l}\text { Conditioning regimen and HPC } \\
\text { infusion }\end{array}$ & Inpatient \\
\hline Management of the aplastic phase & At home \\
\hline
\end{tabular}

\subsubsection{Inclusion Criteria for At-Home Allo-HSCT Patients}

Inclusion criteria for at-home allo-HSCT patients: Specifically, apply similar conditions as an at-home auto-HSCT. 


\subsubsection{General Recommendations for At-Home Allo-HSCT}

Apply whole hints described for autoHSCT. Moreover, strictly frequent dosage of IS (2-3 times per week) is recommended. Monitoring of CMV and Aspergillus should not differ from that recommended for conventional allo-HSCT. Primary prophylaxis for Aspergillus is not established but is strongly suggested.

\subsubsection{Which Readmission Criteria?}

Which readmission criteria? Apply similar conditions for ambulatory auto-HSCT plus evidence of GVHD grades II-IV.

\subsubsection{Treatment of Fever in At-Home Setting}

Treatment of fever in at-home setting: See athome auto-HSCT.

\subsubsection{Incidence of Readmission in Outpatient and At-Home Allo-HSCT}

Readmission rate is high (50-80\%, according to the series) mainly due to organ toxicity associated with the preparative regimen in MAC with TBI and use of MTX or CY-PT such as GVHD prophylaxis.

The incidence of infection rate is lower than inpatient modality (15-30\%, according to the series). Particularly, the incidence of Aspergillus or other mold infections was low $(0-7 \%$, according to series).

Severe GVHD is a low frequent cause of readmission in the first 30 days.

This incidence is related to the experience of the group of professionals and by the support infrastructure available in the hospital. In our experience, only 1 of the 28 patients (3.6\%) required hospital readmission.

\subsubsection{Quality of Life and Cost}

The limited experience seems to show that athome allo-HSCT modality improves nutrition/ caloric intake, physical activity, and welfare of self that probably help to recover quickly and reduce toxicity, minimizing infection risk and GVHD (Svahn et al. 2008; Ringdén et al. 2013). Nevertheless, it is difficult to determine that these measures impact on a reduction of the total cost taking into account that the readmission rate is high and that most experiences include preplanned booking of inpatient beds.

\section{Key Points}

- At home auto-HSCT is feasible and safe with a good selection of patients.

- At home auto-HSCT is cost-effective considering the patient setting, not analyzed in the context of the whole hospital budged.

- $\mathrm{MM}$ is the best indication for at-home auto-HSCT.

- With an adequate selection of patients, at-home allo-HSCT is feasible and safe.

- Allo-HSCT performed with the use of NMA and RIC conditioning regimens is the best option due to their inherent low organic toxicity.

\section{References}

Anastasia A, Giglio F, Mazza R, et al. Early discharge after high-dose melphalan and peripheral blood stem cell reinfusion in patients with hematological and non-hematological disease. Leuk Lymphoma. 2009;50:80-4.

Faucher C, Le Corroller Soriano AG, Esterni B, et al. Randomized study of early hospital discharge following autologous blood SCT: medical outcomes and hospital costs. Bone Marrow Transplant. 2012;47:549-55.

Fernández Avilés F, Carreras E, Urbano-Ispizua A, et al. Case-control comparison of at home to total hospital care for autologous stem-cell transplantation for hematologic malignancies. J Clin Oncol. 2006;24:4855-61.

Holbro A, Ahmad I, Cohen S, et al. Safety and costeffectiveness of outpatient autologous stem cell trans- 
plantation in patients with multiple myeloma. Biol Blood Marrow Transplant. 2013;19:547-51.

Martino M, Montanari M, Ferrara F, et al. Very low rate of re-admission after an early discharge outpatient model for autografting in multiple myeloma patients: an Italian multi-center retrospective study. Biol Blood Marrow Transplant. 2014;20:1026-32.

Martino M, Lemoli RM, Girmenia C, et al. Italian consensus conference for the outpatient autologous stem cell transplantation management in multiple myeloma. Bone Marrow Transplant. 2016;51:1032-40.

Martino M, Ciavarella S, De Summa S, et al. A comparative assessment of quality of life in patients with multiple myeloma undergoing autologous stem cell transplantation through an outpatient and inpatient model. Biol Blood Marrow Transplant. 2018;24:608-13.

McDiarmid S, Hutton B, Atkins H, et al. Performing allogeneic and autologous hematopoietic SCT in the outpatient setting: effects on infectious complications and early transplant outcomes. Bone Marrow Transplant. 2010;45:1220-6.

Meisenberg BR, Miller WE, McMillan R, et al. Outpatient high-dose chemotherapy with autologous stem-cell rescue for hematologic and nonhematologic malignancies. J Clin Oncol. 1997;15:11-7.

Meisenberg BR, Ferran K, Hollenbach K, et al. Reduced charges and costs associated with outpatient autologous stem cell transplantation. Bone Marrow Transplant. 1998;21:927-32.

Morabito F, Martino M, Stelitano C, et al. Feasibility of a mixed inpatient-outpatient model of peripheral blood stem cell transplantation for multiple myeloma. Haematologica. 2002;87:1192-9.

Ringdén O, Remberger M, Holmberg K, et al. Many days at home during neutropenia after allogeneic hematopoietic stem cell transplantation correlates with low incidence of acute graft-versus-host disease. Biol Blood Marrow Transplant. 2013;19:314-20.
Ringdén O, Sadeghi B, Moretti G, et al. Long-term outcome in patients treated at home during the pancytopenic phase after allogeneic haematopoietic stem cell transplantation. Int J Hematol. 2018;107:478-85.

Schulmeister L, Quiett K, Mayer K. Quality of life, quality of care, and patient satisfaction: perceptions of patients undergoing outpatient autologous stem cell transplantation. Oncol Nurs Forum. 2005;32:57-67.

Scortechini I, Montanari M, Mancini G, Inglese E, Calandrelli M, Chiarucci M, Offidani M, Capelli D, Gini G, Poloni A, Mancini S, Raggetti G, Leoni P, Olivieri A. Conditioning regimen with BCNU, etoposide, cytarabine and melphalan plus amifostine for outpatient autologous stem cell transplant: feasibility and outcome in 97 patients with lymphoma. Leuk Lymphoma. 2014;55:1657-60.

Solomon SR, Matthews RH, Barreras AM, et al. Outpatient myeloablative allo-SCT: a comprehensive approach yields decreased hospital utilization and low TRM. Bone Marrow Transplant. 2010;45:468-75.

Summers N, Dawe U, Stewart DA. A comparison of inpatient and outpatient ASCT. Bone Marrow Transplant. 2000;26:389-95.

Svahn BM, Remberger M, Myrback KE, et al. Home care during the pancytopenic phase after allogeneic hematopoietic stem cell transplantation is advantageous compared with hospital care. Blood. 2002;100:4317-24.

Svahn BM, Remberger M, Heijbel M, et al. Case-control comparison of at-home and hospital care for allogeneic hematopoietic stem-cell transplantation: the role of oral nutrition. Transplantation. 2008;85:1000-7.

Westermann AM, Holtkamp MMJ, Linthorst GAM, et al. At home management of aplastic phase following high-dose chemotherapy with stem-cell rescue for hematological and non-hematological malignancies. Ann Oncol. 1999;10:511-7.

Open Access This chapter is licensed under the terms of the Creative Commons Attribution 4.0 International License (http://creativecommons.org/licenses/by/4.0/), which permits use, sharing, adaptation, distribution and reproduction in any medium or format, as long as you give appropriate credit to the original author(s) and the source, provide a link to the Creative Commons license and indicate if changes were made.

The images or other third party material in this chapter are included in the chapter's Creative Commons license, unless indicated otherwise in a credit line to the material. If material is not included in the chapter's Creative Commons license and your intended use is not permitted by statutory regulation or exceeds the permitted use, you will need to obtain permission directly from the copyright holder.

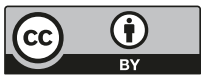

